\title{
Calcineurin Is an Antagonist to PKA Protein Phosphorylation Required for Postmating Filamentation and Virulence, While PP2A Is Required for Viability in Ustilago maydis
}

\author{
John D. Egan,, María D. García-Pedrajas, ${ }^{2}$ David L. Andrews, ${ }^{1}$ and Scott E. Gold ${ }^{1}$ \\ ${ }^{1}$ Department of Plant Pathology, University of Georgia, Athens, GA 30602-7274, U.S.A.; 'Estación Experimental "La Mayora", \\ CSIC, 29760 Algarrobo-Costa, Málaga, Spain
}

Submitted 22 December 2008. Accepted 25 May 2009.

\begin{abstract}
Ustilago maydis is a dimorphic basidiomycete and the causal agent of corn smut disease. It serves as a genetic model for understanding dimorphism, pathogenicity, and mating response in filamentous fungi. Previous studies indicated the importance of regulated cAMP-dependent protein kinase A (PKA) for filamentous growth and pathogenicity in $U$. maydis. The roles of two protein phosphatases that potentially act antagonistically to PKA were assessed. A reverse genetics approach to mutate the catalytic subunits of calcineurin $(\mathrm{CN}$, protein phosphatase $[\mathrm{PP}] 2 \mathrm{~B})$ and PP2A in $U$. maydis was employed. A mutation in the $C N$ catalytic subunit ucn1 caused a dramatic multiple-budding phenotype and mating between two ucnl mutants was severely reduced. The pathogenicity of $u c n 1$ mutant strains was also severely reduced, even in a solopathogenic haploid strain. Importantly, mutations disrupting protein phosphorylation by PKA were epistatic to ucn1 mutation, indicating a major role of ucn1 as a PKA antagonistic phosphatase. Genetic and inhibitor studies indicated that the $U$. maydis PP2A catalytic subunit gene (upa2) was essential.
\end{abstract}

Ustilago maydis, the causal agent of corn smut disease, is a heterothallic basidiomycete (Christensen 1963). In the haploid stage, $U$. maydis exists as a saprobic budding yeast that undergoes a dimorphic switch to become an infectious filamentous dikaryon. To generate this filamentous dikaryon, two compatible haploid yeast strains differing at two genetic loci (termed $a$ and $b$ ) must mate (Bakkeren et al. 2008; Banuett 1995; Holliday 1961; Kahmann et al. 1995; Kronstad and Staben 1997). Two pathways are known to play antagonistic roles in regulating this dimorphic switch, the cAMP-protein kinase A (PKA) pathway and the pheromone-response mitogen activated protein kinase pathway (Andrews et al. 2000; Mayorga and Gold 1998, 1999, 2001; Müller et al. 1999).

Inhibition of the PKA pathway through mutations inactivating the adenylate cyclase protein (Uac1) or the catalytic subunit of PKA (Adr1) results in a constitutively filamentous

Corresponding author: Scott E. Gold; Telephone: +1.706 .542 .1259 ; Fax: +1.706.542.1262; E-mail: sgold@uga.edu

Current address for J. D. Egan: Dept. of Biology, Salisbury University, Salisbury, MD 21801-6837, U.S.A.

*The $\boldsymbol{e}$-Xtra logo stands for "electronic extra" and indicates that a supplementary figure is published online. phenotype that is reverted by addition of exogenous cAMP (Durrenberger et al. 1998; Gold et al. 1994, 1997). Hyperactivation of this pathway through mutation of the regulatory subunit of PKA (Ubc1), on the other hand, induces a multiplebudding phenotype that is not affected by cAMP levels (Gold et al. 1994). Interestingly, all these mutations in the PKA pathway that alter the haploid phenotype (e.g., multiple budding $u b c l$ mutant strain or the haploid filamentous adrl or uacl mutant strains) cause a reduction in mating and pathogenicity (Durrenberger et al. 1998; Gold et al. 1994, 1997; Larraya et al. 2005), which provides strong evidence that the phosphorylation state of PKA substrates are determinants of morphology and pathogenicity. This phosphorylation state is a result of the dynamic interplay of protein kinases and protein phosphatases. While considerable data has accumulated on the action of protein kinases, particularly PKA, in $U$. maydis, the role of the phosphatases is largely unexplored. With this in mind, we were interested in the protein phosphatases that may act antagonistically to PKA. In this work, we specifically targeted two candidate protein phosphatases, calcineurin $(\mathrm{CN})$ and protein phosphatase 2A (PP2A), for functional characterization.

The $\mathrm{CN}$ holoenzyme is comprised of three polypeptides, a catalytic subunit, a calcium-activated regulatory subunit, and calcium-activated calmodulin (Kincaid 1993; Shenolikar 1994; Stie and Fox 2008). There are documented examples in which $\mathrm{CN}$ has been shown to act antagonistically to PKA. In Saccharomyces cerevisiae, PKA and $\mathrm{CN}$ act antagonistically on the Zn-finger transcription factor $\mathrm{Crz} 1 \mathrm{p} / \mathrm{Tcn} 1 \mathrm{p}$, which is involved in ion and cell-wall synthesis regulation (Hirata et al. 1995; Matheos et al. 1997; Stathopoulos and Cyert 1997). CN dephosphorylates $\mathrm{Crz} 1 \mathrm{p} / \mathrm{Tcn} 1 \mathrm{p}$, allowing it to accumulate in the nucleus for gene transcription, while cAMP-dependent PKA negatively regulates $\mathrm{Crz} 1 \mathrm{p} / \mathrm{Tcn} 1 \mathrm{p}$ activity by inhibiting its nuclear import through phosphorylation (Kafadar and Cyert 2004). In plant pathogens and other fungi, $\mathrm{CN}$ has recently been shown to play roles in morphogenesis, cell cycle, circadian rhythms, and virulence (Campos et al. 2008; da Silva Ferreira et al. 2007; Fox and Heitman 2005; Harel et al. 2006; Kullas et al. 2007; Schumacher et al. 2008; Steinbach et al. 2006).

PP2A is also a heterotrimeric protein complex with documented activities antagonistic to PKA. It comprises one catalytic subunit and two regulatory subunits (Shenolikar 1994; Stark 1996). This phosphatase is known to act antagonistically to PKA in the regulation of glycogen metabolism in Saccharomyces cerevisiae (Clotet et al. 1995; Müller et al. 2000). Re- 
cently, it has been found that PP2A plays a key role in limiting phosphorylation of targets by PKA during cardiac myocyte contraction responses (de Arcangelis et al. 2008). Among the roles ascribed to PP2A in plant pathogen and other fungal species are the regulation of hyphal morphogenesis, sporulation, secondary metabolism, and the circadian clock (Choi and Shim 2008; Erental et al. 2007; Schafmeier et al. 2005; Yang et al. 2004; Yatzkan et al. 1998). In Candida albicans, Sit4, a protein phosphatase related to PP2A, plays a role in dimorphic growth and virulence (Lee et al. 2004). Interestingly, a possible substrate for PP2A is PKA itself. The catalytic subunit of mammalian PKA has been shown to autophosphorylate a threonine residue (Thr-197), which is essential for its optimal activity (Cauthron et al. 1998). Liauw and Steinberg (1996) have suggested that PP2A (or a closely related enzyme) can dephosphorylate Thr-197 on the catalytic subunit of PKA, thereby reducing its optimal activity.

In the current work, we investigated potential antagonistic roles of $\mathrm{CN}$ and PP2A with respect to PKA in $U$. maydis. Our central hypothesis pertinent to this report was that, although disruption of a protein phosphatase antagonistic to PKA phosphorylation events in a wild-type background would generate a multiple-budding phenotype similar to that of $u b c l$ mutants, disruption of this activity in strains with an inactive PKA pathway would have no visible phenotypic effect. We therefore employed a candidate-gene approach to mutate these two suspected PKA-antagonistic protein phosphatase genes, ucnl, en-

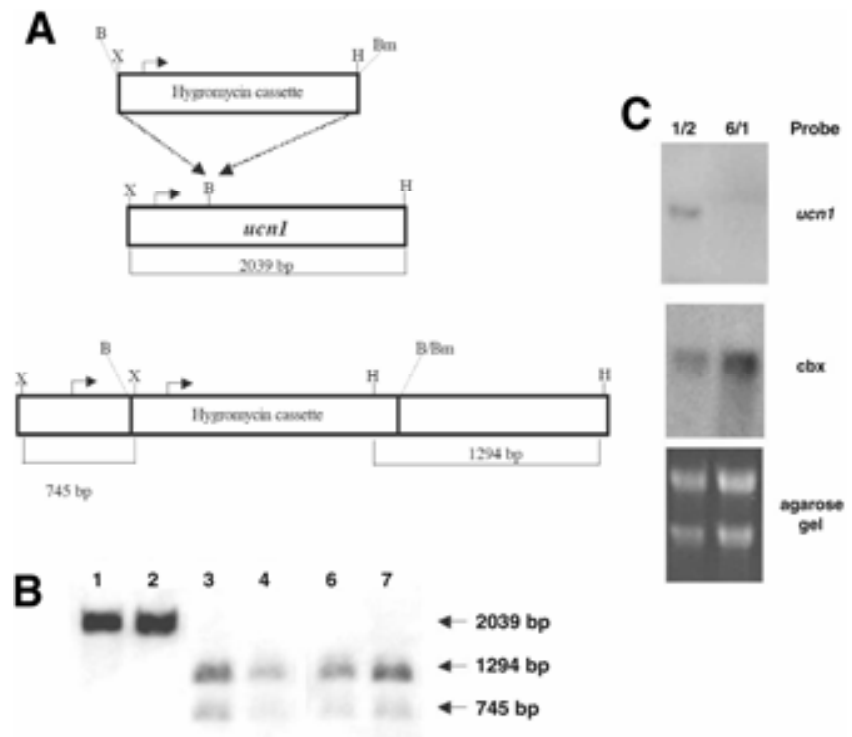

Fig. 1. Mutation of ucnl. A, ucnl disruption construct strategy. A BglII (B)-Bam $\mathrm{HI}(\mathrm{Bm})$ hygromycin phosphotransferase cassette from pIC19RHL was inserted into a $B g l \mathrm{II}$ site in the center of the catalytic core of $u c n 1$. Restriction enzyme digests of Ustilago maydis ucn 1 disrupted strains with $X b a \mathrm{I}(\mathrm{X})$ and HindIII $(\mathrm{H})$ were predicted to produce two bands (1,294 and 745 bp), while the wild-type ucnl gene should produce a single larger band (2,039 bp). Bent arrows indicate the direction of transcription. B, Southern blot analysis of $u c n 1^{-}$strains. Genomic DNA was extracted from the $U$. maydis tranformants, digested with $\mathrm{XbaI}$ and HindIII (fragments were resolved through $0.8 \%$ agarose) and transferred to a positively charged nylon membrane. A digoxigenin-labeled ucn1 probe was hybridized to the membrane according to the manufacturer's instructions. Lane 1, 1/2 (wild-type), lane 2, SG200 (solopathogenic haploid), lane 3, 6/1 (ucn1 $\left.1^{-}\right) a 1 b 1$, lane 4, 6/9 (ucn1 $\left.{ }^{-}\right) a 2 b 2$, lane 6, 6/26 (SG200 ucn $1^{-}$), and lane 7, 6/27 (SG200 ucn $1^{-}$). C, Northern analysis of $1 / 2$ (wild-type) and strain $6 / 1\left(u c n 1^{-}\right)$. Strains were grown in potato dextrose broth for $30 \mathrm{~h}$. RNA was isolated and subjected to Northern blot analysis after loading approximately $15 \mu \mathrm{g}$ of total RNA per lane. Lane 1 is the $1 / 2$ wild-type strain, lane 2 is the 6/1 ucn 1 disrupted strain. A second hybridization with the carboxin (succinate dehydrogenase) gene probe and the transferred EtBr agarose gel are shown as loading controls. coding a CN catalytic subunit, and upa2, encoding a PP2A catalytic subunit. Generally consistent with our hypothesis, we found that ucnl mutants exhibit a multiple-budding phenotype similar to that of $u b c l$ mutants, except that the former can form much larger cell clusters. Mating and pathogenicity were also compromised in ucnl mutants. Epistasis analysis through the use of double mutants, the $\mathrm{CN}$ inhibitor cyclosporin $\mathrm{A}$ (CsA), or both indicated that $\mathrm{CN}$ is required for filamentation induced by heterozygosity at the mating type loci in the solopathogenic haploid strain SG200 but not in haploid cAMP pathway mutants.

A PP2A (upa2) gene disruption was not obtained in a haploid strain, suggesting that the gene might be essential. Consistent with this finding, $U$. maydis was extremely sensitive to okadaic acid (OA; $2 \mathrm{nM}$ ), a PP2A inhibitor. upa2 was confirmed to be essential through segregation analysis employing a solopathogenic diploid strain mutated for one copy of upa2.

\section{RESULTS}

\section{Cloning and analysis of ucn1 and upa2.}

To clone the gene (prior to genome data release) encoding the catalytic subunit of $\mathrm{CN}$, which we designated ucn 1, degenerate primers OSG06 and OSG12 were designed according to known CN catalytic subunit genes, based on the conserved sequence of the catalytic core and the regulatory subunit-binding domain (Means 1994). A polymerase chain reaction (PCR) fragment (7.94 bp) was amplified from wild-type strain $1 / 2$ genomic DNA and was cloned and sequenced. Using a PCRbased, sib selection strategy (Banuett and Herskowitz 1994), the full-length cosmid clone, cosucn1, was recovered from a genomic cosmid library (Barrett et al. 1993). The ucnl gene was sequenced to reveal an uninterrupted open reading frame of 1,881 nucleotides coding for a polypeptide of 627 amino acids (aa) (accession number AY271263, um00936). Comparisons with database entries demonstrated striking similarities to other fungal CN catalytic subunits (Supplementary Fig. S1).

The gene encoding the catalytic subunit of PP2A was cloned in a similar manner in the initial PCR step; because of the conservation between PP2A and PP2B sequences, degenerate primer OSG06 was also used but, in this case, in combination with primer OSG10, based on a sequence conserved in many protein phosphatases. This gene was designated upa 2 and consisted of 1,038 nucleotides with a $120 \mathrm{bp}$ intron spanning nucleotides 478 to 597 (accession number AY538590, um11525). The putative 306 amino acid-encoded polypeptide had strong similarities to other PP2A catalytic subunits (data not shown). A search of the $U$. maydis genome indicates that there are no apparent additional functional paralogs to these phosphatases.

$\mathrm{Ucn} 1(\mathrm{CN})$ plays a role in morphogenesis in $U$. maydis.

A mutant allele of $u c n l$ was generated by inserting a hygromycin-resistance cassette 10 amino acids upstream from the conserved phosphatase activation site RGNHE (Fig. 1). The ucn $1:$ hyg allele was used to transform wild-type strain $1 / 2$. Replacement of the $u c n l$ wild-type copy by the mutated allele in strain 6/1 (Table 1) was verified through DNA and RNA blot hybridization analysis (Fig. 1). The ucnl mutant had altered morphology in liquid and on solid culture media. In liquid culture, strain 6/1 showed a strong cell-separation defect (multiple budding) (Fig. 2A and C) reminiscent of $u b c l$ mutants but even more extreme. We observed that addition of cAMP had no effect on this mutant phenotype. The ucnl mutant colonies were convoluted and with depressed centers and raised margins as compared with wild type (Fig. 2B and D). Complementation of the $\mathrm{CN}$ mutant with plasmid pUCN1 containing a wildtype copy of $u c n l$ regenerated the wild-type budding pattern 
and colony morphology (Fig. 2E and F). As compared with $u b c 1$ mutants (Gold et al. 1994) in which cell clusters possess up to about 15 cells, ucn1 mutant clusters may have up to several thousand cells and could be observed macroscopically (Fig. 3A and B). 4',6-Diamidino-2-phenylindole staining revealed a single nucleus per cluster cell in ucnl mutants (Fig. 3C). To test for pathogenicity defects independent of mating, ucnl was also mutated in the solopathogenic haploid strain SG200 (al::mfa2 bE1bW2), generating strains $6 / 26$ and $6 / 27$. The SG200 ucn1 mutants had a colony phenotype that strongly resembled the $u c n l$ mutant in a wild-type haploid background (data not shown).

\section{CsA treatment recapitulates the ucn1 mutant phenotype in strains with functional PKA activity, but has no effect on uac1 or adr1 mutants.}

CsA is a specific inhibitor of CN (Cardenas et al. 1994). At concentrations of $10 \mu \mathrm{g} / \mathrm{ml}$, CsA-induced phenotypes in wildtype $U$. maydis strains were indistinguishable from the ucnl mutant (Fig. 4B and C). The addition of CsA to ucnl mutant strains had no effect on morphology (Fig. 4C and D).

The effect of CsA was tested on several other genotypes to help establish the role of $u c n 1$ in generation of specific phenotypes. The phenotype of SG200 grown in the presence of CsA was indistinguishable from that of the ucnl mutant in a wildtype haploid background (Fig. 4B, I, and J) or from the phenotype of the SG200 ucn1 mutant strain (data not shown). Similar results were observed when CsA was added to the solopathogenic diploid strain $\mathrm{d} 132$ (data not shown). The multiplebudding $u b c 1$ mutant strain (1/68) also assumed a phenotype typical of the $u c n 1$ mutant upon addition of CsA (Fig. 4E and F). Importantly the filamentous $a d r l$ mutant strain appeared unaffected by addition of CsA (Fig. 4G and H). Similarly the
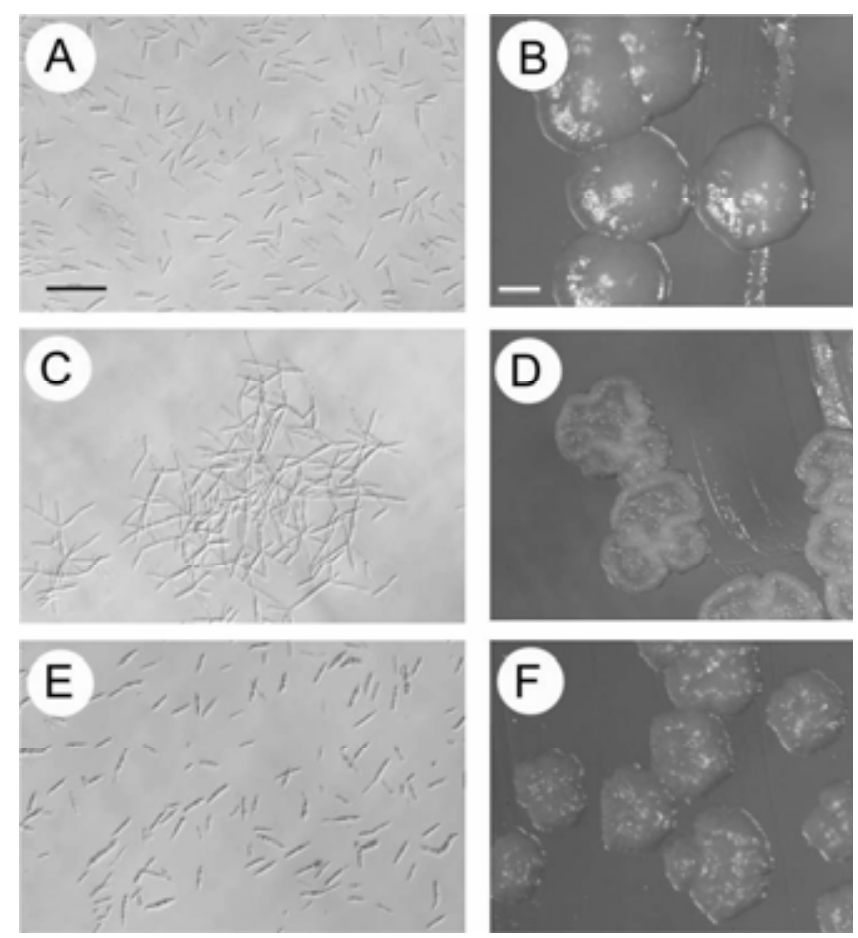

Fig. 2. Cell and colony morphology of Ustilago maydis ucn1 mutants. A, $\mathbf{C}$, and $\mathbf{E}$, Cell morphology of various $U$. maydis strains grown overnight in potato dextrose broth. $\mathbf{B}, \mathbf{D}$, and $\mathbf{F}$, Colony morphology of various $U$. maydis strains grown on potato dextrose agar for 4 days at $30^{\circ} \mathrm{C}$. Left panels, $b a r=50 \mu \mathrm{m}$ and right panels, $b a r=1 \mathrm{~mm}$. Strains are as follows: $\mathrm{A}$ and $\mathrm{B}, 1 / 2$ (wild-type), $\mathrm{C}$ and $\mathrm{D}, 6 / 1$ (ucn $^{-}$), $\mathrm{E}$ and $\mathrm{F}, 6 / 64$ (ucn1 $1^{-}+$ pUCN1). uacl mutant did not respond to CsA (data not shown). These data indicate that an $a d r l$ but not a $u b c l$ mutation is epistatic to the ucnl mutant phenotype (Fig. 4E through H). Consistent with the result for adrl, a uacl mutation is also epistatic to the ucnl inactivation (data not shown). These results are consistent with our original hypothesis for a major PKA antagonistic role of $\mathrm{CN}$ in acting to dephosphorylate PKA substrates.

To explore the formation of the ucnl mutant phenotype, we carried out a timecourse experiment to determine bud site selection during $\mathrm{CN}$ inhibition. After setting wild-type cell cultures to $\mathrm{G}_{0}$ (Ruiz-Herrera et al. 1995) and adding CsA, we observed growing cultures over a 10 -h period of time. In $U$. maydis wild-type growth conditions, mother cells produce a single daughter bud at one pole, which when mature, is released via cell separation (Jacobs et al. 1994). However, after the addition of CsA, the mother cells first formed a central septation; buds then formed from both ends of the mother cell, which indicated that the first possible cell division was within the mother cell (Fig. 5B and C, arrows). After $8 \mathrm{~h}$, a definite pattern was identified, in which buds continued to form from the mother cell and subsequent daughter cells. In addition to polar budding, by $10 \mathrm{~h}$, the mother cell produced 2 or 3 long buds forming at its center septum (Fig. 5D, arrows). A diagram indicating the order of bud emergence was produced, generations are denoted with numbers in Figure 5E. The budding pattern of the ucnl mutant strains is consistent with this pattern of budding induced by CsA.

Table 1. Strains of Ustilago maydis and plasmids used in this study

\begin{tabular}{|c|c|c|}
\hline Strain & Relevant genotype & Source \\
\hline $1 / 2$ & al b1 also known as strain 521 & Gold et al. 1997 \\
\hline $2 / 9$ & $\begin{array}{l}a 2 b 2(\mathrm{BX} 7 \mathrm{~A} 22, \text { near isogenic } \\
\text { to } 1 / 2)\end{array}$ & Gold et al. 1997 \\
\hline $1 / 9$ & al b1 uacl::ble & Gold et al. 1997 \\
\hline $1 / 68$ & al b1 ubcl::hyg & Gold et al. 1994 \\
\hline $2 / 21$ & d132 diploid (ala2 b1b2) & Kronstad and Leong 1989 \\
\hline $6 / 1$ & al b1 ucn $1:$ hyg & This study \\
\hline $6 / 9$ & a2 b2 ucn $1::$ hyg & This study \\
\hline $6 / 26$ & SG200 ucn1:: hyg & This study \\
\hline $6 / 27$ & SG200 ucn $1::$ hyg & This study \\
\hline $6 / 55$ & al b1 adrl::ble & Durrenberger et al. 1998 \\
\hline $6 / 77^{\mathrm{b}}$ & d132 upa $2::$ hyg & This study \\
\hline $6 / 78^{c}$ & d132 upa $2::$ hyg ectopic & This study \\
\hline $7 / 20$ & SG200 (a1::mfa2 bE1bW2) & Müller et al. 1999 \\
\hline pUCN1 & $\begin{array}{l}U C N 1 \text { gene } c b x^{R} \text { inserted into } \\
\text { pCM619 }\end{array}$ & This study \\
\hline pCM619 & $c b x^{R}$ plasmid & Kojic and Holloman 2000 \\
\hline
\end{tabular}

a uacl gene disruption with phleomycin marker.

b One copy of upa2 replaced by upa2::hyg allele.

c upa2::hyg construct integrated ectopically.
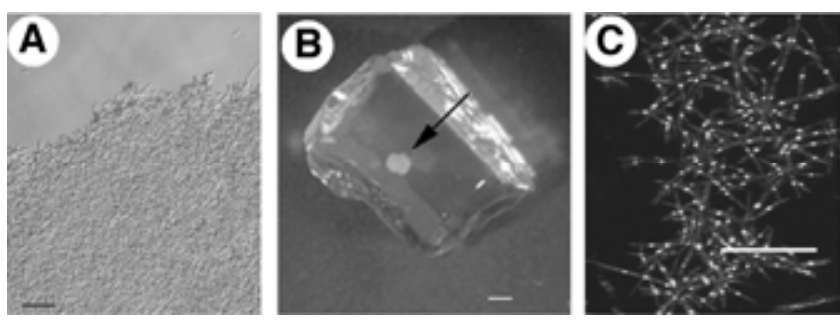

Fig. 3. Cell clusters and nuclear condition of $u c n 1$ mutant cells. The ucn 1 mutant strain grown for $30 \mathrm{~h}$ in potato dextrose broth is shown. A, Cell cluster containing several thousand unseparated cells. B, One large cluster was pipetted into molten $1 \%$ agarose and was solidified for photography under a steriomicroscope. C, 4',6-Diamidino-2-phenylindole staining of cell cluster shows single nuclei in each budded cell. A and C, Bar $=50 \mu \mathrm{m}$ and $\mathrm{B}, 1 \mathrm{~mm}$. 
Ucn1 plays pre- and postmating roles in pathogenicity.

The ucn 1 mutant $(6 / 1, a 1 b 1)$ was crossed in maize plants to the wild-type strain $(2 / 9, a 2 b 2)$ to produce teliospores. Segregation analysis indicated that 43 of 48 hygromycin-resistant progeny from these teliospores had the typical $u c n 1^{-}$multiplebudding phenotype. This result showed a high degree of cosegregation of the mutant phenotype with resistance to hygromycin. The presence of a small number of resistant segregants that did not exhibit the multiple-budding phenotype can be explained by aneuploidy or suppressor mutant generation that are often encountered in $U$. maydis. Through this cross, progeny strain 6/9 was identified as a $u c n 1$ mutant in an $a 2 b 2$ matingtype background and was used in further experimentation.

To determine the effect of the ucnl mutation on cell fertility, charcoal plate mating assays (Holliday 1974) were carried out. In matings between compatible wild-type strains $(1 / 2 \times 2 / 9)$, very strong white filamentous growth was observed $24 \mathrm{~h}$ after co-spotting (Fig. 6). However, when one strain was disrupted in ucnl $(1 / 2 \times 6 / 9$ or $2 / 9 \times 6 / 1)$, a significantly reduced reaction was observed. If both mating partners had ucnl disrup-
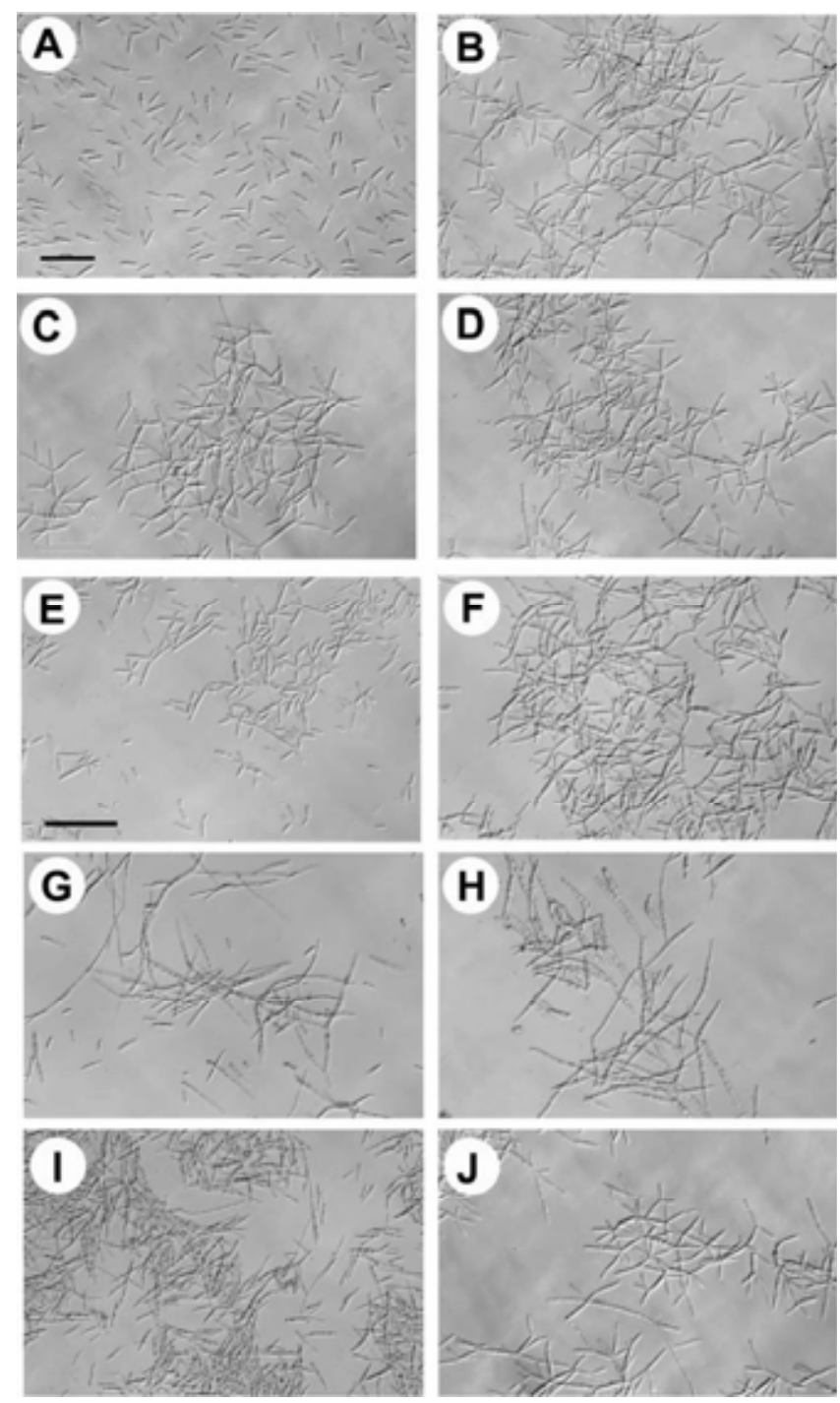

Fig. 4. Epistasis analysis of cAMP pathway mutants and calcineurin function. On the left, strains grown overnight in potato dextrose broth; on the right, the same strains grown with the addition of cyclosporin A (CsA) at $10 \mu \mathrm{g} / \mathrm{ml}$. Bar $=50 \mu \mathrm{m}$. Strains are as follows: A, $1 / 2$ (wild type), B, $1 / 2+$ CsA, C, 6/1 (ucn $\left.1^{-}\right), \mathbf{D}, 6 / 1+\mathrm{CsA}, \mathbf{E}, 1 / 68\left(u b c l^{-}\right), \mathbf{F}, 1 / 68+\mathrm{CsA}, \mathbf{G}$, 6/55 (adrl $\left.{ }^{-}\right), \mathbf{H}, 6 / 55+\mathrm{CsA}, \mathbf{I}$, SG200 (solopathogenic haploid), and J, SG200 + CsA. tions $(6 / 1 \times 6 / 9)$, a very weak mating reaction occurred after $24 \mathrm{~h}$. These data indicate that ucnl mutants were blocked in efficient formation of filamentous dikaryons during mating.

To determine the effect of mutation of the ucnl gene on pathogenicity, maize plants were inoculated with various pairwise combinations of wild-type and ucnl single-mutant compatible mating partners. Pathogenicity assays were repeated at least three times with typical results shown in Table 2. The ucnl gene acted as a critical virulence and pathogenicity factor, since $u c n l$ disruption mutants never induced tumors upon inoculation and were capable of inducing only sparse localized chlorosis on 40 to $60 \%$ of inoculated plants (Table 2). The ucnl mutation was recessive, as mutants combined with the compatible wild-type strains produced typical disease symptoms comparable to wild-type mating combinations. Fungal hyphae were never observed within the plant when two ucnl mutants were crossed (data not shown). Loss of virulence in crosses of compatible ucnl mutants could be due to either a pre- or postmating defect or a combination thereof. To differentiate between pre- and postmating effects, pathogenicity tests were performed employing the solopathogenic haploid SG200, which bypasses the requirement for mating, and its derivative $u c n 1$ mutants. While SG200 itself caused significant
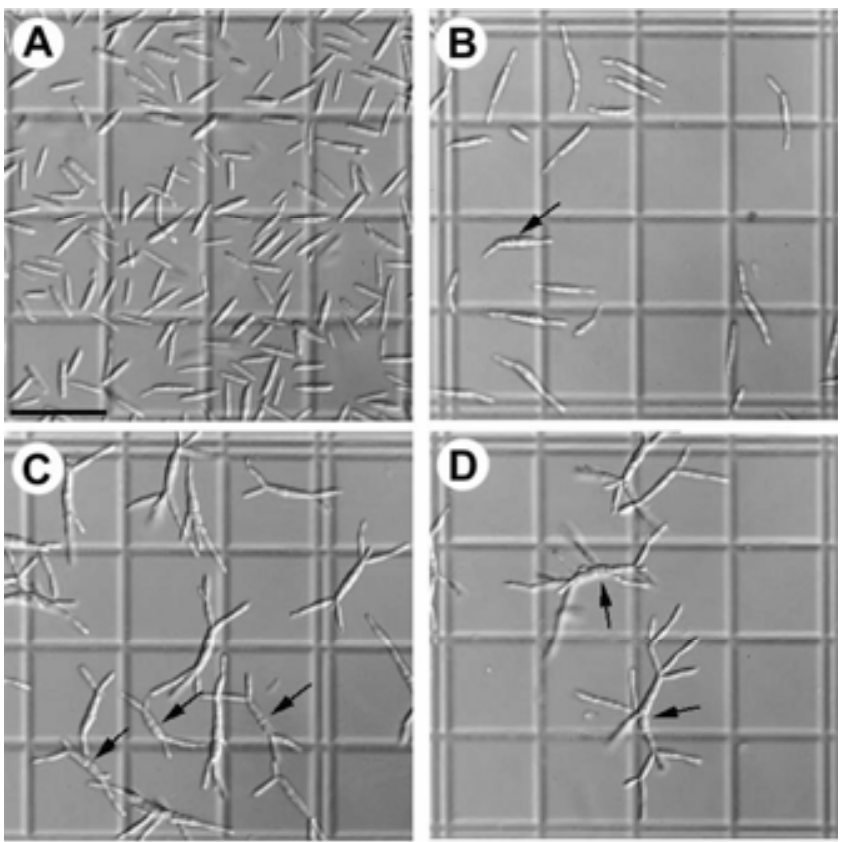

E

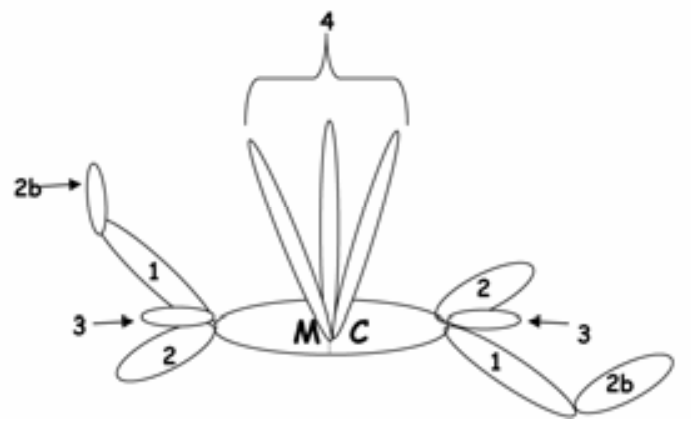

Fig. 5. Timecourse of cell division after the addition of cyclosporin A (CsA). A timecourse of synchronized wild-type cells (1/2) after the addition of CsA at the rate of $10 \mu \mathrm{g} / \mathrm{ml}$. A 100-ml culture of wild-type $1 / 2$ was grown in potato dextrose broth overnight. The culture was set to $\mathrm{G}_{0}, \mathrm{CsA}$ was added, and photographs were taken at $\mathbf{A}, 0, \mathbf{B}, 4, \mathbf{C}, 8$, and $\mathbf{D}, 10 \mathrm{~h}$. The experiment was replicated three times with similar results. Arrows indicate the center septation of the mother cell. Bar $=50 \mu \mathrm{m}$. E, Schematic of budding order $(\mathrm{MC}=$ mother cell). 
disease, the SG200 ucnl mutant strains (6/26 or 6/27) showed highly reduced pathogenicity and, similarly to the inoculations with the $6 / 1 \times 6 / 9$ haploid ucnl mutant combination, caused no tumor formation (Table 2). Microscopic observation of maize seedlings inoculated with a SG200 ucnl mutant strain demonstrated that multiple-budding cell clusters were abundant on the plant epidermis around inoculation sites but there was no evidence of ramifying hyphae (data not shown). Taken together, the data suggest a major postmating role for $u c n l$ in pathogenicity. This data shows that although the absence of tumors in the $6 / 1 \times 6 / 9$ crosses could be the result of the inability of these strains to mate and produce an infectious dikaryon, Ucn1 also plays a major role on pathogenicity independent of mating.

\section{Upa2 (PP2A) is essential for $U$. maydis cell viability.}

A upa 2 disruption construct was made that destroyed the catalytic core coding region of the phosphatase $2 \mathrm{~A}$ catalytic subunit and replaced it with a hygromycin-resistance cassette

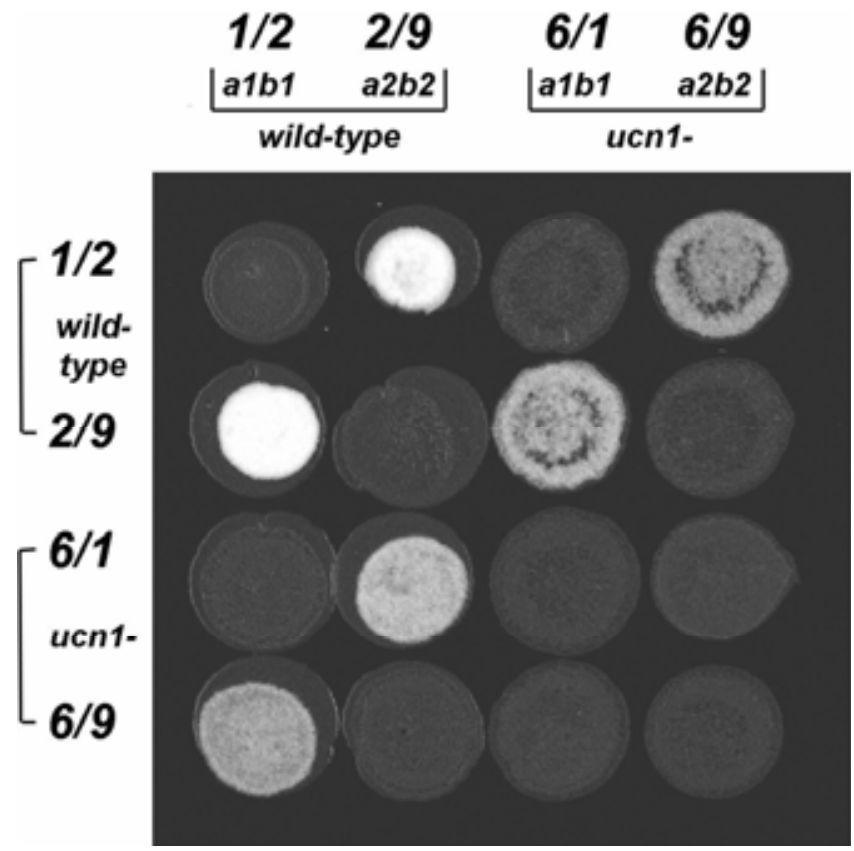

Fig. 6. Effect of the ucn1 mutation on mating. Spots $(5 \mu \mathrm{l})$ of overnight cell cultures were placed on charcoal-containing medium. Rows were first placed and dried in a transfer hood, and then, columns were spotted. Mating reactions were incubated at $30^{\circ} \mathrm{C}$ and were photographed $24 \mathrm{~h}$ postinoculation. (data not shown). Five separate transformation attempts were made to disrupt upa2 in the wild-type haploid strain 1/2. All the 95 hygromycin-resistant transformants analyzed were determined to have ectopic integration events (data not shown). The rate of homologous integration in $U$. maydis is usually $>10 \%$, so the lack of transformants in which gene replacement had taken place suggested that upa 2 might be essential.

The potential role of Upa2 in U. maydis was also investigated through the use of inhibitors. OA, a potent inhibitor of PP2A (Cohen et al. 1990), was used on the wild-type strain 1/2 in a cell growth assay. At low OA concentrations $(2 \mathrm{nM}), U$. maydis cells appeared swollen (Fig. 7B). As the concentration of OA was increased, cells became more spherical in shape (Fig. 7C through E), while at the highest concentration tested, $12 \mathrm{nM}$ OA, cells appeared to lyse (Fig. 7F). Cell counts taken at 12 and $28 \mathrm{~h}$ revealed that at 2 and $4 \mathrm{nM}$ OA, cells underwent only two division cycles (starting cell concentration of $1 \times 10^{5}$ to a final cell concentration of $4 \times 10^{5}$ ), while at $8 \mathrm{nM} \mathrm{OA}$, cells completed only one division (final concentration of cells
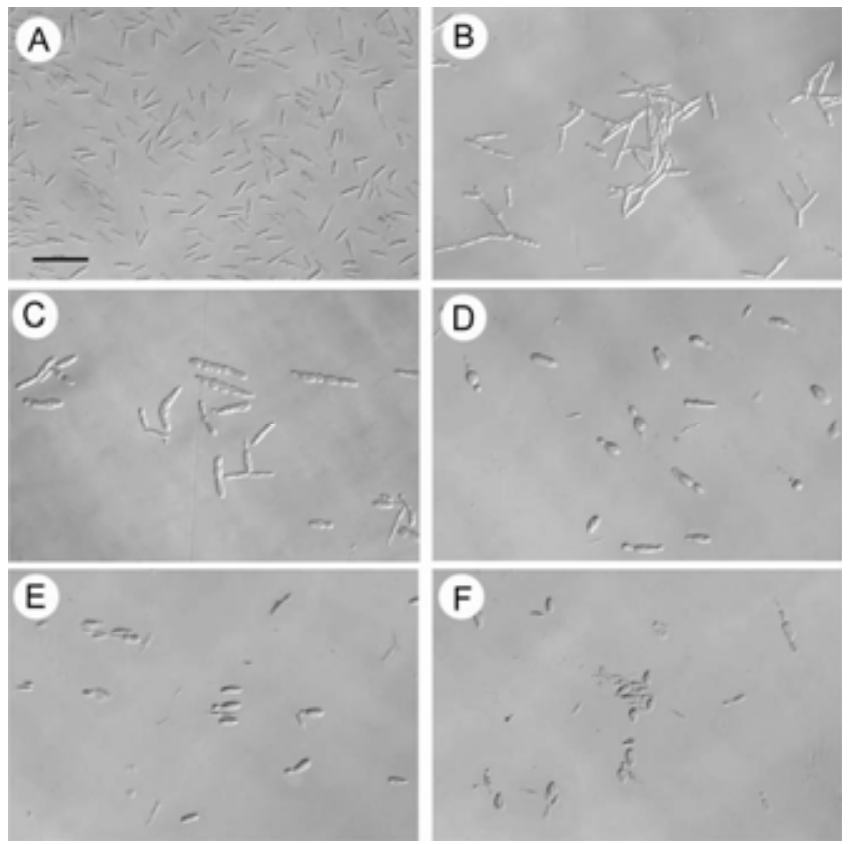

Fig. 7. Effect of okadaic acid (OA) on the growth of Ustilago maydis. Wild-type strain $1 / 2$ grown $30 \mathrm{~h}$ in potato dextrose broth with different concentrations of OA. A, 0, B, 2, C, 3, D, 4, E, 8, and F, $12 \mathrm{nM}$.

Table 2. Pathogenicity of $u c n 1$ mutants $^{\mathrm{a}}$

\begin{tabular}{|c|c|c|c|c|c|c|c|c|c|}
\hline \multirow[b]{2}{*}{ Treatment $^{\mathrm{c}}$} & \multirow[b]{2}{*}{ ucnl genotype } & \multirow[b]{2}{*}{ No. of plants } & \multicolumn{6}{|c|}{ Disease rating $^{b}$} & \multirow[b]{2}{*}{ Disease index ${ }^{d}$} \\
\hline & & & $\mathbf{0}$ & 1 & 2 & 3 & 4 & 5 & \\
\hline 1 & $+/+$ & 20 & $\ldots$ & $\ldots$ & 4 & 2 & $\ldots$ & 12 & 3.70 \\
\hline 2 & $+/ u c n 1^{-}$ & 20 & $\ldots$ & 3 & 5 & 1 & $\ldots$ & 11 & 3.55 \\
\hline 3 & ucn1 $1^{-} /+$ & 20 & $\ldots$ & 2 & 5 & 2 & $\ldots$ & 11 & 3.65 \\
\hline 4 & ucn $1^{-} /$ucn $1^{-}$ & 20 & 8 & 12 & $\ldots$ & $\ldots$ & $\ldots$ & $\ldots$ & 0.60 \\
\hline $5^{e}$ & SG200+ & 20 & $\ldots$ & 3 & 1 & 12 & 3 & 1 & 2.90 \\
\hline 6 & $6 / 26$ ucn $^{-}$ & 20 & 12 & 8 & $\ldots$ & $\ldots$ & $\ldots$ & $\ldots$ & 0.40 \\
\hline 7 & 6/27 ucn1- & 20 & 13 & 7 & $\ldots$ & $\ldots$ & $\ldots$ & $\ldots$ & 0.35 \\
\hline
\end{tabular}

${ }^{a}$ Results of one of three tests. All results were similar.

${ }^{\mathrm{b}}$ Recorded 14 days postinoculation.

${ }^{\mathrm{c}}$ Treatments were inoculations of $10^{6}$ cells per milliter for all wild-type strains $(+)$ and $10^{7} \mathrm{CFU}$ (cell clusters) per milliter for all mutant strains $\left(u c n 1^{-}\right)$. Paired strains are as follows: $1=1 / 2$ and $2 / 9,2=1 / 2$ and 6/9, $3=6 / 1$ and 2/9, $4=6 / 1$ and 6/9, $5=$ SG200 (solopathogenic haploid), $6=6 / 26$ (ucn $1^{-}$ SG200), $7=6 / 27$ (ucn $1^{-}$SG200).

${ }^{\mathrm{d}}$ Disease index is calculated as $\Sigma$ disease ratings divided by the number of plants. Disease ratings are described as follows: $0=$ no disease; $1=$ anthocyanin or chlorosis; 2 = leaf galls; 3 = small stem galls; 4 = large stem galls; 5 = plant death due to disease.

e Solopathogenic haploids have a lower disease rating than two compatible haploid strains. Also note that treatments 5 to 7 were with solopathogenic haploids that should be able to cause disease without needing a mating partner. 
$\left.2 \times 10^{5}\right)$. The fact that no homologous integrants were identified combined with the inhibitor data suggested that the loss of PP2A activity likely resulted in lethality in $U$. maydis.

To further corroborate lethality of upa 2 mutation, a copy of the gene was replaced by the upa2::hyg mutant allele in a solopathogenic diploid strain, to determine whether haploid progeny lacking the wild-type upa 2 gene were viable. The resulting upa2 heterozygous strain (6/77) retained pathogenicity. Strain 6/77 was inoculated into plants to generate teliospores from which segregating progeny were derived. Following teliospore germination, progeny were analyzed for the ability to grow in the presence of hygromycin, and PCR was employed to determine the presence of a disrupted upa 2 allele. Only four of 96 progeny obtained from strain 6/77 were hygromycin resistant. A chi-square test for a fit to a predicted 1:1 segregation ratio gave a probability of $<0.005$, clearly indicating that the result did not conform to standard segregation of two alleles at a single gene. All four hygromycin-resistant segregants generated both the wild-type upa2 and mutant upa $::$ hyg allelic bands when PCR amplified (data not shown). Additionally, three of the hygromycin-resistant segregants grew with a typical diploid fuzzy-colony morphology on charcoal mating plates. Together, these data suggest that hygromycin-resistant strains derived from 6/77 teliospores were either

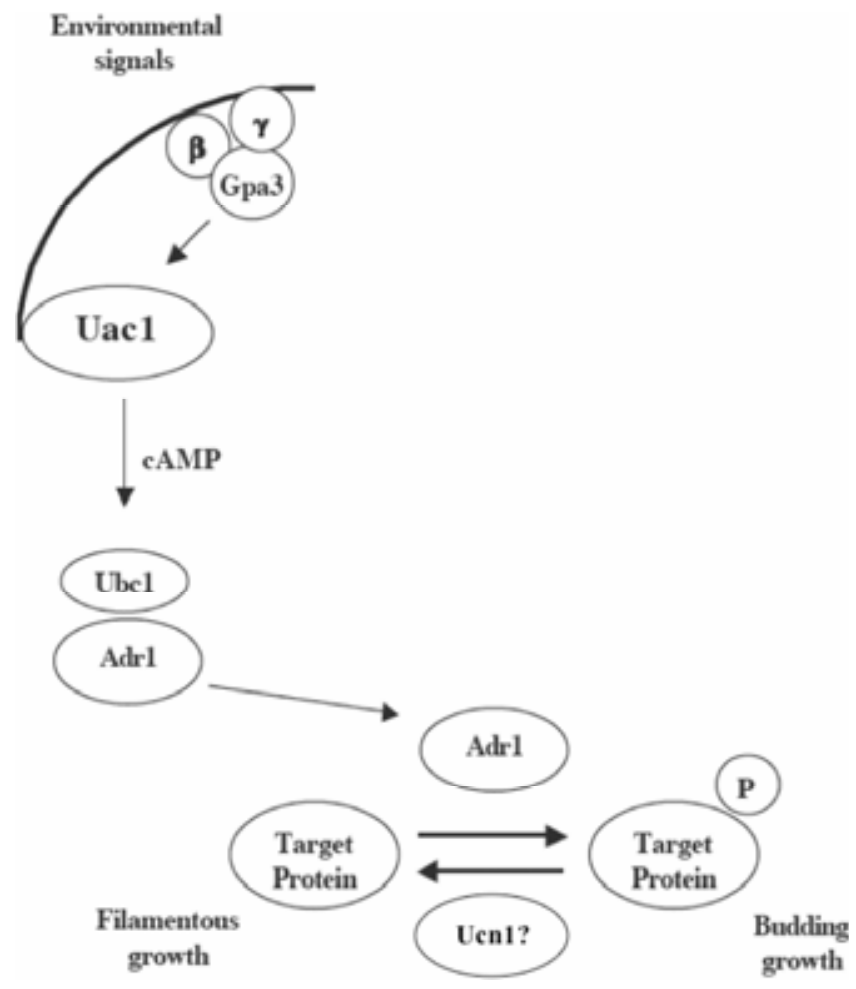

Fig. 8. Proposed model for the hypothetical role of Ucn1 in the Ustilago maydis cAMP pathway. Environmental signals activate a cell-surface receptor that transmits a signal through a trimeric G-protein (Gpa3 being important for signal transmission). It is presumed that Gpa3 activates Uac1, which converts ATP to the secondary signal molecule cAMP. Cyclic AMP then binds to the regulatory subunit of protein kinase A (PKA) (Ubc1), inducing a conformational change causing the release of the catalytic subunit of PKA (Adr1). Adr1 is then able to phosphorylate target proteins responsible for haploid budding morphology. In a uacl mutant, invasive filamentous growth is seen in the haploid state. As predicted by the model, inhibition of Ucn1 activity by cyclosporin A has no effect on $\mathrm{uac} 1$ or adrl mutants, which continue to filament. Ucn1 lacks substrates to dephosphorylate in these mutants and, thus, has no impact on morphogenesis. The question mark after Ucn1 indicates our continuing uncertainty of the definite and unique role of Ucn1 in removing phosphate groups on Adr1 substrates. rare diploids or aneuploids and that no haploid hygromycinresistant progeny were obtained. In contrast, eight of 14 colonies generated by germination of teliospores produced by strain $6 / 78$, in which the upa2::hyg allele had integrated ectopically, were hygromycin resistant. This result is consistent with a 1:1 segregation ratio, as determined by the chi-square test. These data corroborated that the absence of a functional wildtype upa 2 allele is lethal.

\section{DISCUSSION}

One of our laboratory's primary goals has been to identify fungal genes that are determinants of dimorphism and pathogenicity. As part of that goal, we describe here the characterization of two protein phosphatases, $\mathrm{CN}$ and $\mathrm{PP} 2 \mathrm{~A}$, potential antagonists of PKA activity. A forward genetic screen using haploid filamentous strain $u a c 1^{-}$led to the characterization of a number of suppressors of filamentous growth (Andrews et al. 2000; Barrett et al. 1993; Gold et al. 1994, 1997; Mayorga and Gold 1998). Because we anticipated that a uacl mutant phenotype would be epistatic to a loss of protein phosphatase activity on target substrates and therefore a forward genetics approach would not be able to identify antagonists to PKA activity, we took a reverse genetic approach in this study. To understand the roles of these genes in aspects of the $U$. maydis life cycle regulated at least in part by PKA, such as morphogenesis and pathogenicity, we attempted to generate mutant alleles in both ucn1 and upa2 encoding a CN and PP2A catalytic subunit, respectively.

We hypothesized that inhibition of these phosphatase activities would lead to hyperphosphorylation of PKA target substrates similarly to what occurs in $u b c 1$ mutants, in which PKA activity is uninhibited. The haploid strains disrupted for $u c n l$, encoding the catalytic subunit of $\mathrm{CN}$, indeed exhibited a multiple-budding phenotype as do $u b c 1$ mutants and, like $u b c 1 \mathrm{mu}$ tants, were unable to induce galls. Pharmacological studies using the $\mathrm{CN}$ inhibitor $\mathrm{CsA}$ aided in a further characterization of the relationship between $\mathrm{CN}$ and the PKA pathway in $U$. maydis. First, addition of CsA to a wild-type haploid strain generated a phenotype indistinguishable from the $u c n l$ mutant phenotype, showing that the inhibition worked through this pathway. This inhibitor could, therefore, be employed to understand possible epistatic relationships between $u c n l, u b c l, u a c l$, and $a d r l$. The prediction that mutation of $u c n l$ is epistatic to mutation of $u b c l$ was supported by the observations that addition of CsA to $u b c l$ mutant cells generated a phenotype indistinguishable from the $u c n l$ mutant, while exogenous addition of cAMP had no impact on the ucnl mutant phenotype. In contrast, the $u a c l$ and $a d r l$ mutants were morphologically unaffected by the presence of CsA. In uacl and adrl mutants, PKA target proteins required for budding growth are presumably not phosphorylated and are therefore unavailable for dephosphorylation by phosphatases and a filamentous phenotype results. Using CsA, we showed that the uacl and adrl mutant phenotype is independent of $\mathrm{CN}$ activity, consistent with the hypothesis that $\mathrm{CN}$ acts antagonistically to PKA in U. maydis morphogenesis (Fig. 8).

Deletion of ucnl also had a dramatic impact on mating and pathogenicity. Defects in the formation and stability of a filamentous dikaryon can originate pre- or postmating or both and can impact pathogenicity. Charcoal plate mating assays indicated that a dosage-dependent reduction in filamentation occurs with ucnl mutants. SG200 ucnl mutants exhibit the $\mathrm{CN}$ mutant phenotype of multiple-budding cell clusters (data not shown). Consistent with this observation, the diploid strain d132 also exhibited the $\mathrm{CN}$ mutant phenotype when grown in the presence of CsA (data not shown). These results indicate 
that filamentation induced by mating-type gene function requires $\mathrm{CN}$. This is in contrast to the $\mathrm{CN}$-independent filamentation of PKA pathway mutants.

Regarding PP2A, attempts to produce mutants in a haploid background were unsuccessful, suggesting that this gene is essential in this fungal species. The observation that wild-type $U$. maydis cells became morphologically distorted when grown in the presence of OA and that cell growth was halted provided further evidence to support this hypothesis. In Schizosaccharomyces pombe and Saccharomyces cerevisiae, PP2A is believed to play a role in cytoskeleton organization and cell-wall integrity (Evans and Stark 1997; Kinoshita et al. 1996; Lin and Arndt 1995). The swollen cell morphology seen after the addition of OA suggests that PP2A may have a similar role in $U$. maydis. Interestingly, reminiscent of the $u b c l$ mutant, at the lowest concentration tested $(2 \mathrm{nM})$ wild-type cells formed multiple-budding cell clusters due to an apparent cell-separation defect (Fig. 7B). This result is consistent with a potential role of PP2A as a repressor in the regulation of PKA or its substrates. We conclusively confirmed genetically that upa2 was an essential gene by mutating one copy of upa 2 in a diploid solopathogenic strain and showing that no haploid progeny harboring the mutant upa2::hyg allele could be recovered from teliospores produced in plants inoculated with this strain.

The reverse genetic approach described here led to two major findings. First, PP2A appears to be required for cell viability in $U$. maydis. Second, mutation of $\mathrm{CN}$ has a dramatic impact on cell morphogenesis, mating, and pathogenicity. This latter result was consistent with our original hypothesis that $\mathrm{CN}$ may function as an antagonist to PKA signaling. The fact that the $u b c l$ mutation was hypostatic to a $u c n l$ mutation suggests that $\mathrm{CN}$ is able to dephosphorylate PKA substrates at a sufficient rate to mask some effects of hyperphosphorylation by PKA. Additionally, the observation that uacl or adrl mutations in which the PKA pathway is inactivated were epistatic to mutation of ucnl suggests that initial phosphorylation of PKA substrates is a prerequisite to observable $\mathrm{CN}$ action. Thus, the use of our reverse genetic approach was validated because, as predicted, mutations in $\mathrm{CN}$ are likely not detectable in a uacl mutant background, as indicated by CsA treatment. Thus, ucnl is not a member of the previously reported $u b c$ mutations that bypass the requirement for adenylate cyclase to generate a budding growth form (Andrews et al. 2000; Gold et al. 1994; Mayorga and Gold 1998).

Finally, because $u c n l$ mutants are defective in virulence and upa 2 mutation is lethal, the protein phosphatases PP2A and $\mathrm{CN}$ appear to be important potential targets for fungal disease control in $U$. maydis. The use of $\mathrm{CN}$ as a target to control disease has already been suggested in other fungal species (Steinbach et al. 2007; Uppuluri et al. 2008).

\section{MATERIALS AND METHODS}

Fungal and bacterial strains and culture conditions.

All $U$. maydis strains in this study (Table 1) were maintained on potato dextrose agar (PDA) (Difco, Franklin Lakes, NJ, U.S.A.) supplemented to $2 \%$ agar and were grown at $30^{\circ} \mathrm{C}$. Fungal liquid cultures were grown at $250 \mathrm{rpm}$ at $30^{\circ} \mathrm{C}$ in potato dextrose broth (PDB) (Difco). Transformants were grown on double complete medium with $1 \mathrm{M}$ sorbitol (DCM-S) and hygromycin B at the rate of $300 \mu \mathrm{g} / \mathrm{ml}$ (Boehringer Mannheim, Indianapolis, IN, U.S.A.) (Barrett et al. 1993), except that instead of $2 \%$ yeast extract, $0.5 \%$ yeast extract was used (the growth of $u c n 1$ mutants was inhibited by $2 \%$ yeast extract but grew well at $0.5 \%$; data not shown). Resistant meiotic progeny were selected on PDA amended with hygromycin B at $150 \mu \mathrm{g} / \mathrm{ml}$. Escherichia coli DH5 $\alpha$ and DH10B (Gibco BRL,
Gaithersburg, MD, U.S.A.) were used for DNA manipulations (Ausubel et al. 1987). E. coli was grown in or on Luria Bertani (LB) medium amended with appropriate antibiotics.

\section{Nucleic acid manipulations.}

PCR amplifications as well as cloning procedures were carried out with standard techniques (Ausubel et al. 1987). $U$. maydis transformations were performed according to Tsukuda and associates (1988).

For amplification of $u c n 1$, degenerate primers OSG06 (RTI TGYGGIGAYRTICAYGGICART) based on VCGDMHGQY and OSG12 (GTRAAIACRTCCATRAARTTIGG) based on TFVDMFN (where $\mathrm{R}=\mathrm{A}$ or $\mathrm{G} ; \mathrm{Y}=\mathrm{C}$ or $\mathrm{T}$, and $\mathrm{I}=$ inosine) were used with $U$. maydis genomic template DNA from strain $1 / 2$. Reactions contained $50 \mathrm{mM} \mathrm{KCl}, 10 \mathrm{mM}$ Tris, $\mathrm{pH} 8.3,2$ $\mathrm{mM} \mathrm{MgCl}, 0.01 \%$ gelatin, $0.1 \%$ Triton $\mathrm{X}-100,10 \mu \mathrm{M}$ of each dNTP, 50 pmol of each primer, and $2 \mathrm{U}$ of Taq polymerase (Boehringer Mannheim). Reactions were performed under the following conditions: 4 min denaturing at $94^{\circ} \mathrm{C}$, followed by 40 cycles of $94^{\circ} \mathrm{C}$ for $1 \mathrm{~min}, 55^{\circ} \mathrm{C}$ for $1 \mathrm{~min}$, and $72^{\circ} \mathrm{C}$ for $2 \mathrm{~min}$, with an 8 -min final $72^{\circ} \mathrm{C}$ extension dwell after the last cycle. The PCR products were cloned into $\mathrm{pCRampSK}^{+}$(Stratagene, La Jolla, CA, U.S.A.) and were sequenced from the vector primer sites (T7 and M13-48 rev). All sequencing was performed on the ABI Prism 310 Genetic Analyzer (Applied Biosystems, Foster City, CA, U.S.A.) using either the ABI Prism Big Dye or the dRhodamine terminator cycle sequencing reaction kits (PE Applied Biosystems) according to the manufacturer's directions. MacDNAsis PRO v3.5 (Hitachi Software Engineering, San Francisco) was used for DNA and protein sequence analysis. MacDNAsis Higgins alignment was used for all protein sequence comparisons. Primers OSG06 and OSG12 were used to screen a $U$. maydis cosmid genomic library (Barrett et al. 1993) by PCR (conditions same as above) to identify the full-length genomic cosmid clone cosucn1.

To create a $u c n l$ disruption construct, the following procedure was employed. Using sequence-specific primers JDE116 (AC GGATCTCTCTTGCTCACC) and JDE113 (GTGGAAGAAG CCGTTCAGTT), a 2,431-bp PCR product was amplified from cosucn 1 and was cloned into pCR2.1 (Invitrogen, Carlsbad, CA, U.S.A.), and the resulting plasmid was designated pP2B2400. The $B g l$ II site was destroyed in an empty pCR2.1 vector, creating plasmid pCR2.1B. Both pCR2.1B and pP2B2400 were cut with NotI and BamHI. The approximately 2,431-bp insert fragment from pP2B2400 was inserted into pCR2.1B, and the resulting plasmid was designated pP2B2400B. A 2.7-kb (BamHI $B g l I I$ ) hygromycin cassette (from pIC19RHL; Mayorga and Gold 2001) was inserted into a BglII site located in the catalytic core region of $u c n 1$, generating plasmid $\mathrm{pP} 2 \mathrm{~B}: \mathrm{HYG}$. To complement a ucnl mutant strain, plasmid pUCN1 was made by subcloning an approximately 5-kb BamHI fragment from cosucn1 into the BamHI site of pCM619 (Kojic and Holloman 2000).

For upa2 gene isolation degenerate primers, OSG06 and OSG10 (GGRTCIYRCCAIADIARRTCRCA) (where D = A, $\mathrm{G}$, or $\mathrm{T}$ ) were used for amplification of upa 2 from $U$. maydis strain $1 / 2$ genomic DNA. PCR reaction times and cloning procedures were the same as above. The 253-bp PCR product was sequenced (from vector primer sites as above), and specific primers JDE201 (GGCAACTCACCTGATACC) and JDE202 (GTCCAGAGTGTCGATAGACG) were used to screen the $U$. maydis cosmid library to identify cosupa2. The pUPA2 plasmid was generated by subcloning an approximately 6-kb BamHI fragment containing the upa 2 gene from cosupa 2 into the BamHI site of pCM619 (Kojic and Holloman 2000).

A upa 2 deletion construct was made by amplifying a 2,323bp fragment using primers JDE213 (ACAAGAAGGAAAGCC 
GTC) and JDE216 (TGCATCTCATCCCTCTTG) and cloning the fragment into pCR2.1 to produce pUPA2-2.3kb. The cloned fragment was then shuttled from pUPA2-2.3 to pCR2.1B, as described above, to produce plasmid pUPA2-2.3B. Two NruI sites within the catalytic core of the upa 2 gene were cut and $B g l$ II linkers (Promega, Madison, WI, U.S.A.) were ligated onto the resulting blunt ends. The 2.7-kb (BamHI-BglII) hygromycin cassette (from pIC19RHL) replaced this catalytic core fragment, and the resulting plasmid was designated pUPA2::HYG.

\section{Pathogenicity assay.}

Truckers Favorite (Imperial Garden Seed, Athens, GA, U.S.A.) seedlings were grown in sterilized potting soil and, at 7 days, were inoculated according to procedures previously described (Gold et al. 1997; Mayorga and Gold 1999). All ucnl mutant strains were grown overnight, and cell suspensions of $10^{7}$ cells per milliliter were used for inoculations (each cell cluster was considered one point of inoculation and was given a count of one). Disease-symptom data were collected at 7, 10, and 14 days after inoculation. Disease ratings were as previously described (Gold et al. 1997). Experiments to analyze pathogenicity were carried out a minimum of three times.

\section{Plate mating assays.}

For plate mating reactions, charcoal plates were made as previously described by Holliday (1974), except that $0.5 \%$ yeast extract was used instead of $2 \%$ (due to inhibition of $u \mathrm{cnl}$ mutant strain growth by yeast extract) from an overnight PDB culture, $5 \mu \mathrm{l}$ of one mating type was spotted on charcoal plates and was dried in a transfer hood; the respective compatible mating partner was then overlay-spotted in the same manner. After the plates were completely dried, they were wrapped with parafilm and were incubated for $24 \mathrm{~h}$ at $30^{\circ} \mathrm{C}$.

\section{Microscopy.}

Photographs of fungal cell morphology were taken using a FujiFilm digital camera FinePix S1PRO on an Olympus BH-2 microscope with differential interference optics as previously described (Mayorga and Gold 1998).

\section{CsA and OA inhibitor assay procedures.}

CsA (Sigma-Aldrich, Saint Louis) was diluted in $95 \%$ EtOH. For all CsA experiments listed below, 95\% EtOH was used as a negative control. CsA was added to $5 \mathrm{ml}$ of PDB cell culture of $10^{5}$ cells per milliliter to reach a final concentration of $10 \mu \mathrm{g} / \mathrm{ml}$. Cells $(1 \mathrm{ml})$ were removed and centrifuged at $5,000 \times g$ for $5 \mathrm{~min}$ and were resuspended in $10 \mu \mathrm{l}$ of distilled $\mathrm{H}_{2} \mathrm{O}$ for observation. Samples were observed using a hemocytometer. For general inhibitor phenotypic observations, $50 \mu \mathrm{l}$ of a 5-ml PDB overnight culture was added to PDB + CsA (10 $\mu \mathrm{g} / \mathrm{ml}$ ), and cell cultures were grown for $24 \mathrm{~h}$ at $30^{\circ} \mathrm{C}$ before being photographed.

OA sodium salt was purchased also from Sigma and was diluted in distilled $\mathrm{H}_{2} \mathrm{O}$. A 5-ml overnight culture of wild-type strain $1 / 2$ diluted to $10^{5}$ cells per milliliter with PDB. Appropriate amounts of OA were added to each culture and were grown under normal conditions. Cell counts were made at 12 and $28 \mathrm{~h}$, using a hemocytometer. For photography of OA cultures, $1 \mathrm{ml}$ of cells was centrifuged at $5,000 \times g$ for $5 \mathrm{~min}$ and resuspended in $10 \mu \mathrm{l}$ of distilled $\mathrm{H}_{2} \mathrm{O}$.

\section{Segregation analysis.}

The upa 2 disruption construct described above was amplified using primers JDE213 and JDE216. This mutant allele, upa $2:: h y g$, was introduced in diploid strain $\mathrm{d} 132$ by gene replacement of one of the wild-type copies of upa2, generating the mutant strain 6/77 (Table1). PCR amplification of an approximately $2-\mathrm{kb}$ product was used to verify gene replacement of one copy of upa2, using primers MARupa2 (GAATCCACA TGTTAAGGCGC) and the hygromycin primer HYG-OUT (CAGAAACTTCTCGACAGACG). Presence of a wild-type upa2 allele was determined by amplification of the 2,323-bp amplicon, using primers JDE213 and JDE216. Maize seedlings were inoculated with strains $6 / 77$ and 6/78 (ectopically upa $::$ hyg integrated strain; Table 1 ) and teliospores were isolated after mature gall formation. Teliospores were harvested and germinated, and progeny were collected by standard methods (Holliday 1974). Progeny were analyzed for the ability to grow in the presence of hygromycin and their upa2 genotype, tested by PCR as described above.

\section{ACKNOWLEDGMENTS}

We thank J. Kronstad and R. Kahmann for generously providing $U$. maydis strains used in this work. We also thank W. Holloman for plasmid pCM619. We acknowledge support from the U.S. Department of Agriculture National Research Initiation Competitive grant nos. 99-35303-8635 and 01-35319-10139 and from the U.S. National Science Foundation Division of International Programs grant nos. INT-9802638 and INT-0203661 to S. E. Gold.

\section{LITERATURE CITED}

Andrews, D. L., Egan, J. D., Mayorga, M. E., and Gold, S. E. 2000. The Ustilago maydis $u b c 4$ and $u b c 5$ genes encode members of a MAP kinase cascade required for filamentous growth. Mol. Plant-Microbe Interact. 13:781-786.

Ausubel, F. M., Brent, R., Kingston, R. E., Moore, D. D., Seidman, J. G., Smith, J. A., and Struhl, K. 1987. Current Protocols in Molecular Biology. Wiley Interscience, New York.

Bakkeren G., Kämper J., and Schirawski J. 2008. Sex in smut fungi: Structure, function and evolution of mating-type complexes. Fungal Genet. Biol. 45:S15-21.

Banuett, F. 1995. Genetics of Ustilago maydis, a fungal pathogen that induces tumors in maize. Annu. Rev. Genet. 29:179-208.

Banuett, F., and Herskowitz, I. 1994. Identification of fuz7, a Ustilago maydis MEK/MAPKK homolog required for a-locus-dependent and independent steps in the fungal life cycle. Genes Dev. 8:1367-1378.

Barrett, K. J., Gold, S. E., and Kronstad, J. W. 1993. Identification and complementation of a mutation to constitutive filamentous growth in Ustilago maydis. Mol. Plant-Microbe Interact. 6:274-283.

Campos, C. B., Di Benedette, J. P., Morais, F. V., Ovalle, R., and Nobrega, M. P. 2008. Evidence for the role of calcineurin in morphogenesis and calcium homeostasis during mycelium-to-yeast dimorphism of Paracoccidioides brasiliensis. Eukaryot. Cell 7:1856-1864.

Cardenas, M. E., Hemenway, C., Muir, R. S., Ye, R., Fiorentino, D., and Heitman, J. 1994. Immunophilins interact with calcineurin in the absence of exogenous immunosuppressive ligands. EMBO (Eur. Mol. Biol. Organ.) J. 13:5944-5957.

Cauthron, R. D., Carter, K. B., Liauw, S., and Steinberg, R. A. 1998. Physiological phosphorylation of protein kinase A at Thr-197 is by a protein kinase A kinase. Mol. Cell. Biol. 18:1416-1423.

Choi, Y. E., and Shim, W. B. 2008. Functional characterization of Fusarium verticillioides $\mathrm{CPP} 1$, a gene encoding a putative protein phosphatase 2A catalytic subunit. Microbiology 154:326-336.

Christensen, J. 1963. Corn smut caused by Ustilago maydis. Monograph No. 2. American Phytopathological Society, St. Paul, MN, U.S.A.

Clotet, J., Posas, F., Hu, G. Z., Ronne, H., and Arino, J. 1995. Role of protein phosphatase $2 \mathrm{~A}$ in the control of glycogen metabolism in yeast. Eur. J. Biochem. 229:207-214.

Cohen, P., Holmes, C. F. B., and Tsukitani, Y. 1990. Okadaic acid: A new probe for the study of cellular regulation. Trends Biochem. Sci. 15:98102.

da Silva Ferreira, M. E., Heinekamp, T., Härtl, A., Brakhage, A. A., Semighini, C. P., Harris, S. D., Savoldi, M., de Gouvêa, P. F., de Souza Goldman, M. H., and Goldman, G. H. 2007. Functional characterization of the Aspergillus fumigatus calcineurin. Fungal Genet. Biol. 44:219-230.

de Arcangelis, V., Soto, D., and Xiang, Y. 2008. Phosphodiesterase 4 and phosphatase $2 \mathrm{~A}$ differentially regulate $\mathrm{cAMP} /$ protein kinase A signaling for cardiac myocyte contraction under stimulation of beta1 adrenergic receptor. Mol. Pharmacol. 74:1453-1462. 
Durrenberger, F., Wong, K., and Kronstad, J. W. 1998. Identification of a cAMP-dependent protein kinase catalytic subunit required for virulence and morphogenesis in Ustilago maydis. Proc. Natl. Acad. Sci. U.S.A. 95:5684-5689.

Erental, A., Harel, A., and Yarden, O. 2007. Type 2A phosphoprotein phosphatase is required for asexual development and pathogenesis of Sclerotinia sclerotiorum. Mol. Plant-Microbe Interact. 20:944-954.

Evans, D. R. H., and Stark, M. J. R. 1997. Mutations in the Saccharomyces cerevisiae type $2 \mathrm{~A}$ protein phosphatase catalytic subunit reveal roles in cell wall integrity, actin cytoskeleton organization and mitosis. Genetics 145:227-241.

Fox, D. S., and Heitman, J. 2005. Calcineurin-binding protein Cbp1 directs the specificity of calcineurin-dependent hyphal elongation during mating in Cryptococcus neoformans. Eukaryot. Cell 4:1526-1538.

Gold, S., Duncan, G., Barrett, K., and Kronstad, J. W. 1994. cAMP regulates morphogenesis in the fungal pathogen Ustilago maydis. Genes Dev. 8:2805-2816.

Gold, S. E., Brogdon, S. M., Mayorga, M. E., and Kronstad, J. W. 1997. The Ustilago maydis regulatory subunit of a cAMP-dependent protein kinase is required for gall formation in maize. Plant Cell 9:1585-1594.

Harel, A., Bercovich, S., and Yarden, O. 2006. Calcineurin is required for sclerotial development and pathogenicity of Sclerotinia sclerotiorum in an oxalic acid-independent manner. Mol. Plant-Microbe Interact. 19:682-693

Hirata, D., Harada, S., Namba, H., and Miyakawa, T. 1995. Adaptation to high-salt stress in Saccharomyces cerevisiae is regulated by $\mathrm{Ca}_{2}^{+} / \mathrm{cal}$ modulin-dependent phosphoprotein phosphatase (calcineurin) and cAMP-dependent protein kinase. Mol. Gen. Genet. 249:257-264.

Holliday, R. 1961. Induced mitotic crossing over in Ustilago maydis. Genet. Res. 2:231-248.

Holliday, R. 1974. Ustilago maydis. Pages 575-595 in: Handbook of Genetics. Vol 1. R. C. King, ed. Plenum, New York

Jacobs, C. W., Mattichak, S. J., and Knowles, J. F. 1994. Budding patterns during the cell-cycle of the maize smut pathogen Ustilago maydis. Can. J. Botany 72:1675-1680.

Kafadar, K. A., and Cyert, M. S. 2004. Integration of stress responses: Modulation of calcineurin signaling in Saccharomyces cerevisiae by protein kinase A. Eukaryot. Cell 3:1147-1153.

Kahmann, R., Romeis, T., Bolker, M., and Kamper, J. 1995. Control of mating and development in Ustilago maydis. Curr. Opin. Gen. Dev. 5:559-564.

Kincaid, R. 1993. Calmodulin-dependent protein phosphatases from microorganisms to man-A study in structural conservatism and biological diversity. Adv. Second Mess. Phosphoprot. Res. 27:1-23.

Kinoshita, K., Nemoto, T., Nabeshima, K., Kondoh, H., Niwa, H., and Yanagida, M. 1996. The regulatory subunits of fission yeast protein phosphatase 2A (PP2A) affect cell morphogenesis, cell wall synthesis and cytokinesis. Genes Cells 1:29-45.

Kojic, M., and Holloman, W. 2000. Shuttle vectors for genetic manipulations in Ustilago maydis. Can. J. Microbiol. 46:333-338.

Kronstad, J. W., and Leong, S. A. 1989. Isolation of two alleles of the b locus of Ustilago maydis. Proc. Natl. Acad. Sci. U.S.A. 86:978-982.

Kronstad, J. W., and Staben, C. 1997. Mating type in filamentous fungi. Annu. Rev. Genet. 31:245-276.

Kullas, A. L., Martin, S. J., and Davis, D. 2007. Adaptation to environmental pH: Integrating the Rim101 and calcineurin signal transduction pathways. Mol. Microbiol. 66:858-871.

Larraya, L. M., Boyce, K. J., So, A., Steen, B. R., Jones, S., Marra, M., and Kronstad, J. W. 2005. Serial analysis of gene expression reveals conserved links between protein kinase A, ribosome biogenesis, and phosphate metabolism in Ustilago maydis. Eukaryot. Cell 4:20292043.

Lee, C. M., Nantel, A., Jiang, L., Whiteway, M., and Shen, S. H. 2004. The serine/threonine protein phosphatase SIT4 modulates yeast-to-hypha morphogenesis and virulence in Candida albicans. Mol. Microbiol. 51:691-709.

Liauw, S., and Steinberg, R. A. 1996. Dephosphorylation of catalytic subunit of cAMP-dependent protein kinase at Thr-197 by a cellular protein phosphatase and by purified protein phosphatase-2A. J. Biol. Chem. 271:258-263

Lin, F. C., and Arndt, K. T. 1995. The role of Saccharomyces cerevisiae type $2 \mathrm{~A}$ phosphatase in the actin cytoskeleton and in entry into mitosis. EMBO (Eur. Mol. Biol. Organ.) J. 14:2745-2759.

Matheos, D. P., Kingsbury, T. J., Ahsan, U. S., and Cunningham, K. W. 1997. Tcn1p/Crz1p a calcineurin-dependent transcription factor that differentially regulates gene expression in Saccharomyces cerevisiae. Genes Dev. 11:3445-3458.

Mayorga, M. E., and Gold, S. E. 1998. Characterization and molecular genetic complementation of mutants affecting dimorphism in the fungus Ustilago maydis. Fungal Genet. Biol. 24:364-376.

Mayorga, M. E., and Gold, S. E. 1999. A MAP kinase encoded by the $u b c 3$ gene of Ustilago maydis is required for filamentous growth and full virulence. Mol. Microbiol. 34:485-497.

Mayorga, M. E., and Gold, S. E. 2001. The $u b c 2$ gene of Ustilago maydis encodes a putative novel adaptor protein required for filamentous growth, pheromone response and virulence. Mol. Microbiol. 41:1365-1379.

Means, A. R. 1994. Calcium, calmodulin and cell cycle regulation. FEBS (Fed. Eur. Biochem. Soc.) Lett. 347:1-4

Müller, P., Aichinger, C., Feldbrügge, M., and Kahmann, R. 1999. The MAP kinase kpp2 regulates mating and pathogenic development in Ustilago maydis. Mol. Microbiol. 34:1007-1017.

Müller, G., Grey, S., Jung, C., and Bandlow, W. 2000. Insulin-like signaling in yeast: Modulation of protein phosphatase 2A, protein kinase A, cAMP-specific phosphodiesterase, and glycosyl-phosphatidylinositolspecific phospholipase C activities. Biochemistry 39:1475-1488.

Ruiz-Herrera, J., Leon, C. G., Guevara-Olvera, L., and Carabez-Trejo, A 1995. Yeast-mycelial dimorphism of haploid and diploid strains of Ustilago maydis. Microbiology 141:695-703.

Schafmeier, T., Haase, A., Káldi, K., Scholz, J., Fuchs, M., and Brunner, M. 2005. Transcriptional feeback of Neurospora circadian clock gene by phosphorylation-dependant inactivation of its transcription factor. Cell 122:235-246.

Schumacher, J., de Larrinoa, I. F., and Tudzynski, B. 2008. Calcineurinresponsive zinc finger transcription factor CRZ1 of Botrytis cinerea is required for growth, development, and full virulence on bean plants. Eukaryot. Cell 7:584-601.

Shenolikar, S. 1994. Protein serine/threonine phosphatases-New avenues for cell regulation. Ann. Rev. Cell Biol. 10:55-86.

Stark, M. J. R. 1996. Yeast protein serine/threonine phosphatases: Multiple roles and diverse regulation. Yeast 12:1647-1675.

Stathopoulos, A. M., and Cyert, M. S. 1997. Calcineurin acts through the CRZ1/TCN1-encoded transcription factor to regulate gene expression in yeast. Genes Dev. 11:3432-3444.

Stie, J., and Fox, D. 2008. Calcineurin regulation in fungi and beyond. Eukaryot. Cell 7:177-186.

Steinbach, W. J., Cramer, R. A. Jr., Perfect, B. Z., Asfaw, Y. G., Sauer, T. C., Najvar, L. K., Kirkpatrick, W. R., Patterson, T. F., Benjamin, D. K. Jr., Heitman, J., and Perfect, J. R. 2006. Calcineurin controls growth, morphology, and pathogenicity in Aspergillus fumigatus. Eukaryot. Cell. 5:1091-1103.

Steinbach, W. J., Cramer, R. A. Jr., Perfect, B. Z., Henn, C., Nielsen, K., Heitman, J., and Perfect, J. R. 2007. Calcineurin inhibition or mutation enhances cell wall inhibitors against Aspergillus fumigatus. Antimicrob. Agents Ch. 51:2979-2981

Tsukuda, T., Carleton, S., Fotheringham, S., and Holloman, W. K. 1988. Isolation and characterization of an autonomously replicating sequence from Ustilago maydis. Mol. Cell Biol. 8:3703-3709.

Uppuluri, P., Nett, J., Heitman, J., and Andes, D. 2008. Synergistic effect of calcineurin inhibitors and fluconazole against Candida albicans biofilms. Antimicrob. Agents Ch. 52:1127-1132.

Yang, Y., He, Q., Cheng, P., Wrage, P., Yarden, O., and Liu Y. 2004. Distinct roles for PP1 and PP2A in the Neurospora circadian clock. Genes. Dev. 18:255-260.

Yatzkan, E., Szöor, B., Fehér, Z., Dombrádi, V., and Yarden, O. 1998. Protein phosphatase 2A is involved in hyphal growth in Neurospora crassa. Mol. Gen. Genet. 259:523-531. 